\title{
Anatomy of Meckel's Cave and the Trigeminal Ganglion: Anatomical Landmarks for a Safer Approach to Them
}

\section{Meckel Cave ve Trigeminal Ganglionun Anatomisi: Onlara Güvenli Bir Yaklaşım için Anatomik Belirteçler}

Mehmet ARSLAN ${ }^{1}$, Haluk DEDA ${ }^{2}$, Emel AVCI $^{3}$, Alaittin ELHAN ${ }^{4}$, Ibrahim TEKDEMIR ${ }^{4}$, R. Shane TUBBS Gokalp SILAV 6 , Erdal YILMAZ7 , Mustafa Kemal BASKAYA ${ }^{8}$

${ }^{1}$ Yuzuncu Yal University, Faculty of Medicine, Department of Neurosurgery, Van, Turkey

${ }^{2}$ Neurosurgery Clinic, Akay Hospital, Ankara, Turkey

${ }^{3}$ Mersin University, Faculty of Medicine, Department of Neurosurgery, Mersin, Turkey

${ }^{4}$ Ankara University, Faculty of Medicine, Department of Anatomy, Ankara, Turkey

${ }^{5}$ Children's Hospital, Department of Pediatric Neurosurgery, Birmingham, AL, USA

${ }^{6}$ Acıbadem University, Faculty of Medicine, Department of Neurosurgery, Istanbul, Turkey

${ }^{7}$ M.H. Ankara Diskapi Training and Research Hospital, 1st Neurosurgery Clinic, Ankara, Turkey

${ }^{8}$ University of Wisconsin, Department of Neurosurgical Surgery, Madison, USA

Correspondence address: Mehmet ARSLAN / E-mail: arslan2002@hotmail.com

\section{ABSTRACT}

AIM: Surgical approaches to Meckel's cave (MC) are often technically difficult and sometimes associated with postoperative morbidity. The relationship of surgical landmarks to relevant anatomy is important. Therefore, we attempted to delineate quantitatively their anatomy and the relationships between $M C$ and surrounding structures.

MATERIAL and METHODS: With the aid of a surgical microscope, MC and its contents were studied in 15 formalin-fixed cadaver head specimens. Measurements were made and their relationships were observed.

RESULTS: The distance from the zygomatic arch and the lateral end of the petrous ridge to MC was 26.5 and $34.4 \mathrm{~mm}$, respectively. The distance from the arcuate eminence, the facial nerve hiatus, and the foramen spinosum to MC was $16.6,12.8$ and $7.46 \mathrm{~mm}$ respectively. The TG lay $5.81 \mathrm{~mm}$ posterior to the foramen ovale. The distance from the abducens, trochlear and oculomotor nerves to the trigeminal ganglion was $1.87,5.53$ and $6.57 \mathrm{~mm}$ respectively. The distance from the posterior and the anterior walls of the sigmoid sinus to the trigeminal porus was 43.6 and $33.1 \mathrm{~mm}$ respectively. The trigeminal porus was on average $7.19 \mathrm{~mm}$ from the anterior wall of the internal acoustic meatus.

CONCLUSION: The anatomical landmarks as presented herein regarding MC may be used for a safer skull base approach to the region. KEYWORDS: Meckel's cave, Petrous apex, Surgical approach, Trigeminal ganglion, Trigeminal impression

öz

AMAÇ: Meckel cave cerrahi yaklaşımları teknik olarak zordur ve sıklıkla ameliyat sonrası komplikasyonlarla birliktedir. Cerrahi belirteçlerin ilgili anatomiyle ilgisi önemlidir. Bundan dolayı, biz onların anatomisini ve çevre yapılarla ilişkilerini tanımlamaya çalıştık.

YÖNTEM ve GEREÇLER: Cerrahi mikroskopun yardımıyla, Meckel cave ve onun ihtivası formalinle fikse olmuş 15 kadavra başında çalışıldı. Ölçümler yapıldı ve ilişsileri gözlendi.

BULGULAR: Zigamatik arkusun ve petroz kenarın lateral sonunun Meckel cave'e ortalama uzaklığı sırasıyla 26,5 ve 34,4 mm idi. Arkuat eminens, fasiyal sinir hiatus ve foramen spinosumun Meckel cave'e ortalama uzaklığı sırasıyla 16,6, 12,8 ve 7,46 mm idi. Trigeminal ganglion foramen ovale'nin 5,81 mm arkasında yerleşmiştir. Abdusens, trohlear ve okülomotor sinirlerin trigeminal gangliona ortalama uzaklıkları sırasıyla 1,87, 5,53 ve $6,57 \mathrm{~mm}$ idi. Sigmoid sinüsün arka ve ön duvarlarının trigeminal porus'a ortalama uzaklıkları sırasıyla 43,6 ve 33,1 mm idi. Trigeminal porus internal akustik meatusun anterior duvarından ortalama 7,19 mm uzakta idi.

SONUÇ: Meckel cave ile ilgili sunulan anatomik belirteçler ve onların anatomik özellikleri ile ilgili bilgiler bu bölgeye güvenli bir yaklaşım için yararlı olabilir.

ANAHTAR SÖZCÜKLER: Meckel cave, Cerrahi yaklaşım, Petroz apex, Trigeminal ganglion, Trigeminal impression 


\section{INTRODUCTION}

Meckel's cave (MC) is a space between two layers of the dura mater at the petrous apex. The trigeminal ganglion (TG), trigeminal cistern and postganglionic trigeminal rootlets are located within the MC $(2-4,9,12,13,19)$. Surgical approaches to $M C$ are technically challenging and might be associated with morbidity $(8,21,23)$. MC has been well described radiologically $(3-4,13,19)$. Previous studies focused on surgical approaches to $M C$ have reported the morphometric analysis of the petrous bone $(1,5-6,10,17-18,21-23,25,26)$. However, detailed information regarding useful landmarks for approaches to $M C$ is lacking in the literature. This study would be a useful adjunct to the existing literature. As the relationship of surgical landmarks to relevant anatomy is important, the present study attempted to quantitatively delineate their anatomy and the relationship with surrounding neurovascular structures in the middle and posterior fossae.

\section{MATERIAL and METHODS}

Fifteen cadaveric heads ( 25 to 81 years of age at death) were fixed in $10 \%$ formaldehyde and were used to take measurements. This part of the study was performed at the Department of Anatomy, Ankara University, Turkey. Additional 4 heads (8 sides) were used to depict regional anatomy and cerebrovascular relationships. This part of the study was performed at the Department of Neurological Surgery, University of Wisconsin, Madison, USA. Measurements were not taken in these dissections and the vasculature was depicted. These cadaveric heads were injected with colored silicone (red for arteries, blue for veins) to demonstrate the vascular anatomy.

For the part of the study where measurements were taken, the calvaria were opened and the cerebral hemispheres were removed. The brain stem was transected at the level of the quadrigeminal plate in order to preserve relationships of cranial nerves adjacent to the TG. The morphometric relationship between $M C$ and identifiable surface landmarks was determined. The meningeal layer of dura mater forming MC was incised and a triangular structure was revealed. The TG was dissected to reveal its relationship to the subarachnoid space. Relationships between MC, the TG and neurovascular structures were observed and measurements were taken. Extradural dissection to access $M C$ in the middle fossa was then performed from lateral to medial. To demonstrate bony landmarks, the dura mater was peeled away while preserving MC. The medial limit of dural elevation was MC and the lateral limit was the end of the petrous ridge and inner surface of the posterior root of the zygoma. The defined landmark was the middle meningeal artery (MMA) as it emerges from the foramen spinosum (FS). The MMA was divided at the FS. The next landmarks used were the arcuate eminence, the facial nerve hiatus, the greater superior petrosal nerve (GSPN), the horizontal part of the petrous internal carotid artery (ICA), and the foramen ovale (FO). The lateral wall of MC was exposed extradurally. After the middle fossa was investigated, the brain stem was removed. The landmarks on the posterior aspect of the petrous bone were identified. The transverse and sigmoid sinuses (SS) were unroofed using a high-speed drill. The dura covering the posterior surface of the petrous bone anterior to the SS was separated from the posterior pyramid, exposing the internal acoustic meatus (IAM). The SS, the trigeminal porus (TP) and the inferior petrosal sinus were preserved. Anatomic relations with respect to posterolateral approaches to $M C$ were noted and measurements were taken. To examine the trigeminal impression (TI), each division of the TG was transected and the TG was removed. All measurements were performed bilaterally using a digital caliper $(0.01 \mathrm{~mm}$ of precision). The data between right and left sides were analyzed statistically. Statistical analysis was performed using the Student-T test with significance set at $\mathrm{p}<0.05$.

Measurements were taken as follows: The length of the TG (A), the thickness of the TG (B), the width of the TG (C), the length of the TI (D), the width of the TI (E), the medial surface of the posterior root of the zygoma to $M C$ distance $(F)$, the lateral end of the petrous ridge to $M C$ distance $(G)$, the arcuate eminence at the petrous ridge to $M C$ distance $(H)$, the facial nerve hiatus to $M C$ distance $(\mathrm{I})$, the $\mathrm{FS}$ to $\mathrm{MC}$ distance $(\mathrm{J})$, the FO to TG distance (K), FO to the $\mathrm{TI}(\mathrm{L})$, the TG to abducens nerve distance $(\mathrm{M})$, the TG to trochlear nerve distance $(\mathrm{N})$, the TG to oculomotor nerve distance $(\mathrm{O})$, the posterior limit of the SS to the inferolateral edge of the TP distance (P), the anterior limit of the SS to the inferolateral edge of the TP distance (R), the middle point of the anterior lip of the IAM to the inferolateral edge of the TP distance (S), and the inferior petrosal sinus to the lower edge of the TP distance (T) (Figure 1).

\section{RESULTS}

MC was observed as the space between the meningeal layer and the periosteal layer of dura which appeared to be tightly attached to the petrous apex. TG, postganglionic trigeminal roots and subarachnoid cistern were identified within the MC (Figure 2). The width of oval-shaped MC corresponded to the mediolateral diameter of the TG and its length corresponded to the distance from the anterior edge of the TG to the TP. At its superior limit, $M C$ was in close proximity to the cavernous sinus. It almost reached the floor of the middle cranial fossa inferiorly.

The mean mediolateral length, thickness and width of the TG was $16.1,2.52$ and $3.78 \mathrm{~mm}$, respectively. The TG itself, except for a small portion, was anterior to the TI. The length and diameter of the oval-shaped TI was 10.5 and $7.64 \mathrm{~mm}$, respectively. The dimensions of the TG were greater than that of the TI. The relationship of the TG to the dura was complex. Meningeal investment of the anterior surface of the TG was strictly adherent to the surface of the TG; whereas it was only adherent on the anterior third on the posterior surface. This space was related to the infratentorial basal cisterns through the trigeminal porus (Figure 2). Delineation of the arachnoid was difficult with gross dissection. A cleavage plane was apparent between the postganglionic trigeminal rootlets. 
The mean distance between $M C$ and the medial surface of the posterior root of the zygomatic arch was $26.5 \mathrm{~mm}$ and the mean distance between MC and the lateral end of the petrous ridge was $38.4 \mathrm{~mm}$. The arcuate eminence was seen just lateral to the $\mathrm{TI}$ on the petrous ridge and average distance from the arcuate eminence to MC was $16.6 \mathrm{~mm}$. Elevation of the middle fossa dura was limited medially due to adherence to the V3 branch of the trigeminal nerve and the cavernous sinus. During extradural subtemporal retraction, the MMA and the V3 were identified before exiting the skull base through their respective foramina. The skeletonization of the

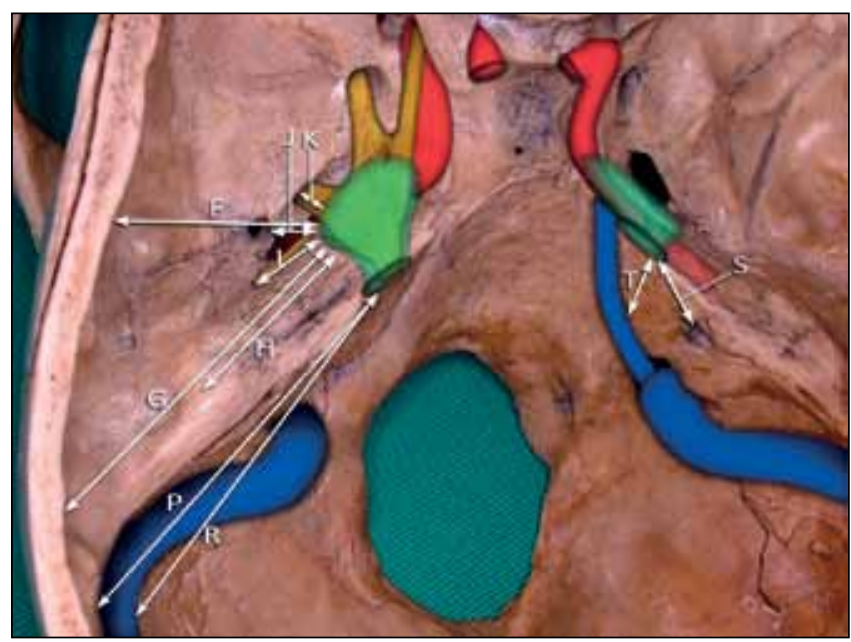

Figure 1: Picture demonstrates measurements taken. F: Medial surface of the posterior root of the zygoma-MC distance, G: Lateral end of the petrous ridge- MC distance, H: Arcuate eminence-MC distance, I: Facial nerve hiatus-MC distance, J: Foramen spinosum-MC distance, K: Foramen ovale-TG distance, P: Posterior limit of the sigmoid sinus- inferolateral edge of TP distance, R: Anterior limit of the sigmoid sinus- inferolateral edge of the TP distance, S: IAM- the inferolateral edge of the TP, T: Inferior petrosal sinus-lower edge of TP distance.

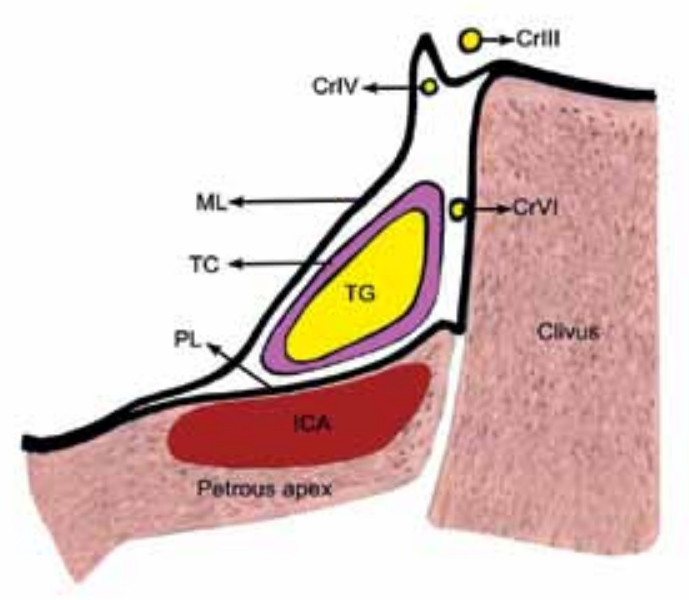

Figure 2: Drawing shows relationship between TG, cranial nerves and dural investment forming MC. ICA: Internal carotid artery, PL: Periostal layer of MC, TC: Trigeminal cistern, ML: Meningeal layer of MC, Cr: Cranial nerve, TG: Trigeminal ganglion.
FS and FO allowed visualization of the lateral wall of MC after releasing the dura and retracting the $\mathrm{V} 3$ medially. The FS was exposed lateral to $M C$ and was found to be $7.46 \mathrm{~mm}$ distance from MC. The FO was found to be always just anterior to MC (the anterior edge of the TG corresponded to the anterior edge of MC) and was positioned $5.81 \mathrm{~mm}$ from the TG, while TI was $7.08 \mathrm{~mm}$ posterior from the FO. The GSPN was found to be posterolateral to $\mathrm{MC}$. It ran medially from the facial nerve hiatus under the dura in its groove and anteriorly behind the V3. The facial nerve hiatus was found on to be $12.8 \mathrm{~mm}$ posterolateral to MC. The horizontal segment of the petrous ICA was always found to be in close proximity to $M C$ just inferior to it. After separating the TG from attached dura, the ICA was extradurally exposed and was mobilized intradurally by sectioning the TG along the junction of the V2 and V3 divisions. The posterolateral part of the cavernous sinus was covered by MC. The TG was separated anteromedially from the ICA by the periostal dura of MC ( Figure 3).

The ocular nerves were all in close proximity to MC (Figures $4,5)$. After leaving the petrous apex, the abducens nerve coursed inferiorly along the lateral wall of the ICA to enter the posteroinferior aspect of the cavernous sinus; at this point, the abducens nerve was in close proximity to the medial aspect of the TG. The mean distance between the TG and the abducens nerve was found to be $1.87 \mathrm{~mm}$. The oculomotor and trochlear nerves were found to be always superior to the TG. The mean distances from the TG were 5.53 and 6.57 $\mathrm{mm}$, respectively. The closest cranial nerve to the TG was the abducens nerve and the farthest was the oculomotor nerve. On the posterior surface of the petrous bone, the mean distance between the posterior edge of the SS and the inferolateral edge of the TP was $43.6 \mathrm{~mm}$ and the TP was on

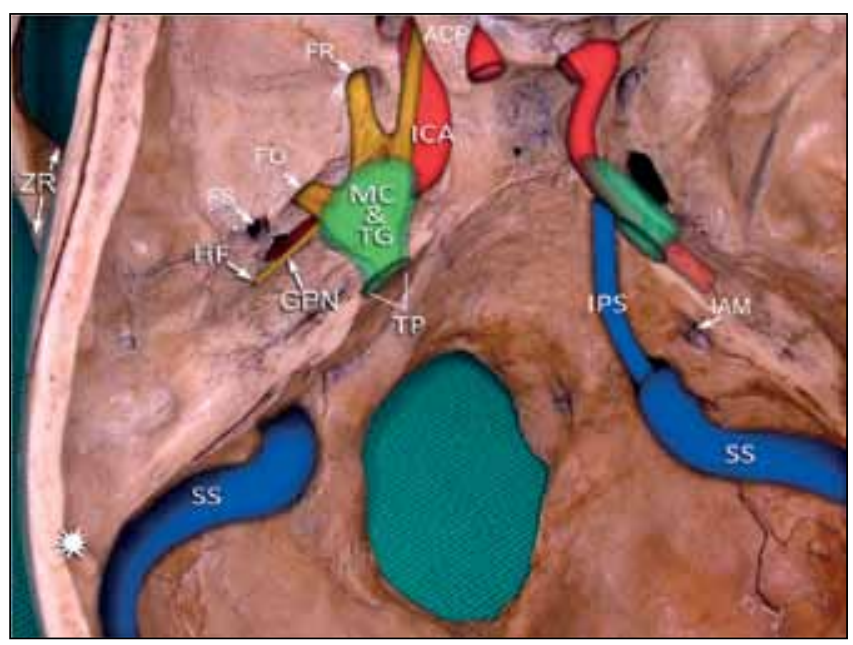

Figure 3: Picture demonstrates anatomical landmarks related to MC. MC: Meckel's cave, TG: Trigeminal ganglion, TP: Trigeminal porus, GPN: Great petrosal nerve, HF: Facial nerve hiatus, FS: Foramen spinosum, FO: Foramen ovale, FR: Foramen rotundum, ACP: Anterior clinoid process, ICA: Internal carotid artery, SS: Sigmoid sinus, ZR: Posterior root of zygomatic arch, IPS: Inferior petrosal sinus, IAM: Internal acoustic meatus,*: Lateral edge of petrous ridge. 


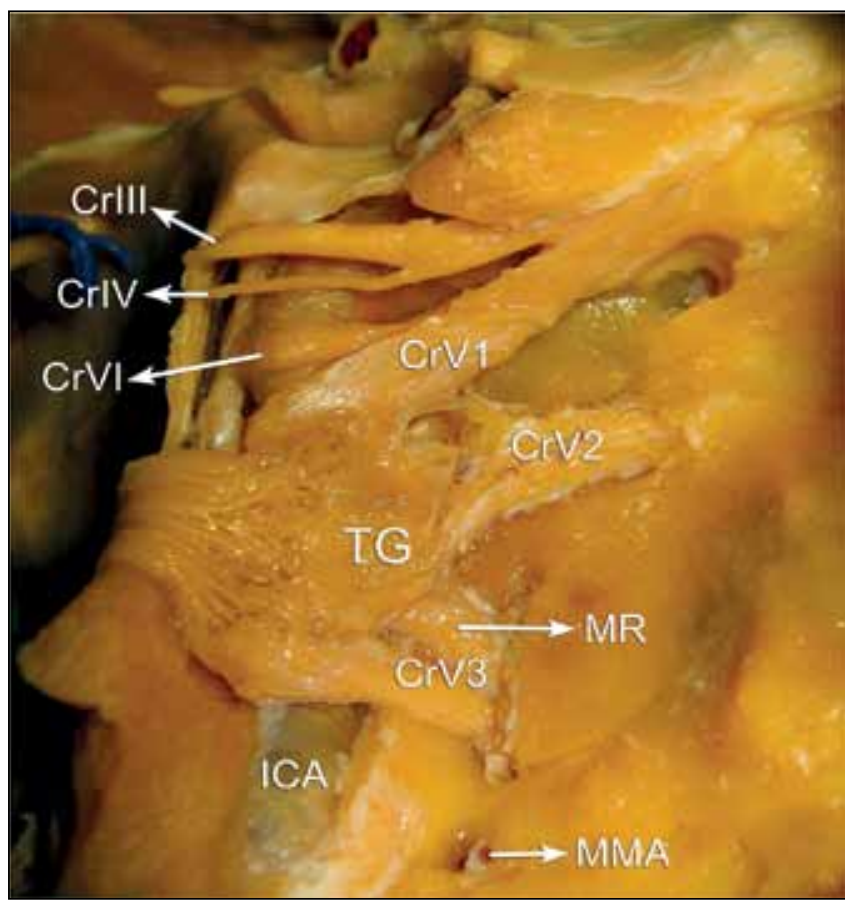

Figure 4: Superior view demonstrating TG and relationships on right side. ICA: Internal carotid artery, Cr: Cranial nerve, TG: Trigeminal ganglion, MMA: Middle meningeal artery, MR: Motor root.

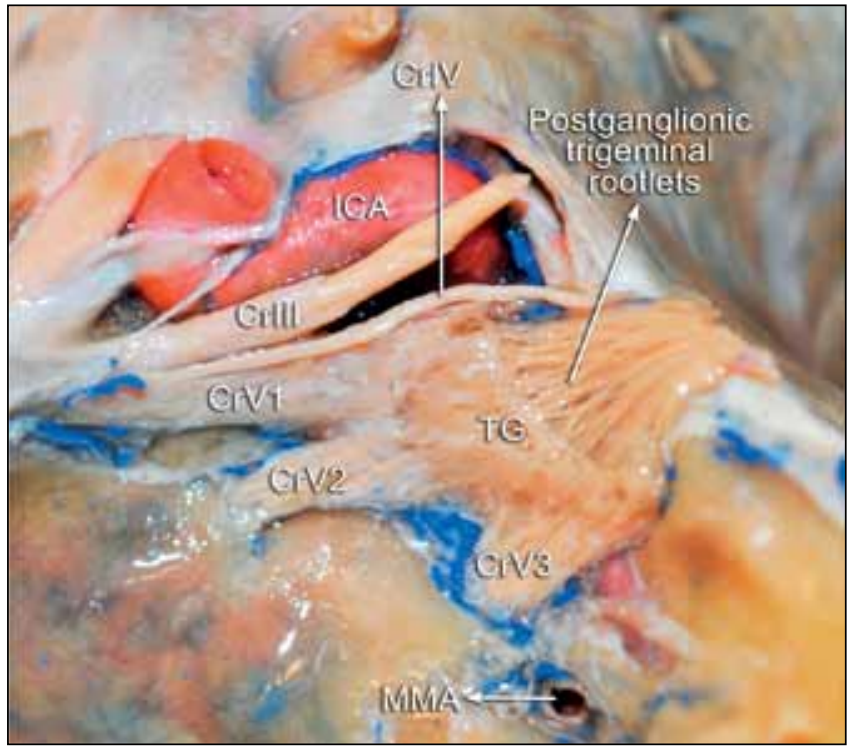

Figure 5: Superolateral view demonstrating of TG and relationships on left side. ICA: Internal carotid artery, Cr: Cranial nerve, TG: Trigeminal ganglion, MMA: Middle meningeal artery.

average, $33.1 \mathrm{~mm}$ from the anterior wall of the SS. Also, the inferolateral edge of the TP was on average $7.19 \mathrm{~mm}$ from the anterior lip of the IAM. The mean distance between the inferior petrosal sinus and the TP was $12.4 \mathrm{~mm}$. Statistically significant differences between the sides were observed for measurements $B, C, D, F, G, H, K, M, N, P, R, S, T(p<0.05)$ (Figure 6, Table I).

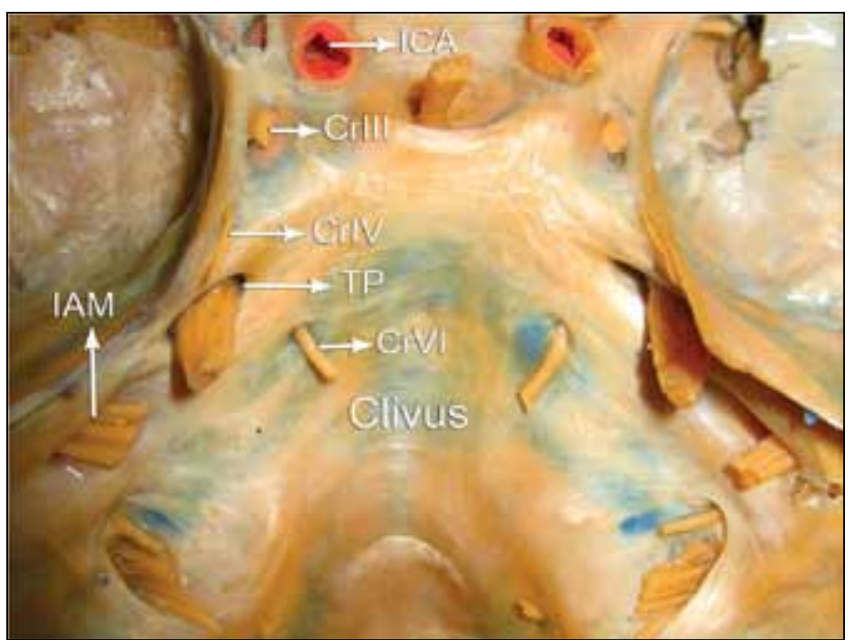

Figure 6: Picture showing morphometric relationships of the structures of the posterior petrosal surface during posterolateral approach MC. ICA: Internal carotid artery, Cr: Cranial nerve, IAM: Internal acoustic meatus.

\section{DISCUSSION}

Tumors arising from $\mathrm{MC}$ represent less than $0.5 \%$ of all intracranial tumors (3). Trigeminal neuromas and meningiomas are most common in this area $(8,15,16,21,23)$. Access to $M C$ might be challenging due to presence of surrounding important neurovascular structures. There are 3 primary surgical corridors to access MC: anterolateral, lateral, and posterolateral. Approaches through these corridors are frontotemporal extradural or intradural, orbitozygomatic, subtemporal anterior petrosal, presigmoid posterior petrosal and suboccipital craniotomies $(6,21,23)$. The choice of approach depends on location and type of pathology, anatomical relationships, familiarity and experience of the surgeon with the approach.

Prior to accessing MC, defining adjacent structures is of great importance. When the subtemporal approach is used to access MC, the posterior root of the zygomatic arch and outer aspect of the temporal bone are first identified. We found that the distance between MC and the zygomatic arch was 26.5 $\mathrm{mm}$. For transtemporal approaches such as infralabyrinthine, translabyrinthine and infracochlear approaches $(7,10)$, the mean distance between $\mathrm{MC}$ and the lateral end of the petrous ridge was $38.4 \mathrm{~mm}$. The arcuate eminence can serve as an anatomic landmark when anterior petrosectomy approach is used $(6,18)$. In a study by Day et al. $(6)$, the distance between the arcuate eminence and the TP was $22.2 \mathrm{~mm}$. In our study, the average distance to MC was $16.6 \mathrm{~mm}$. Using an anterolateral or lateral approach extradurally, the FS and the MMA, which is one of the first deep structures observed, and the FO with the $\mathrm{V} 3$ were most important landmarks for identification of MC. The V3 is identified just below the lateral margin of MC. Accordind to our findings; $M C$ is best identified medial to the FS and just posterior to the FO. Division of MMA and finding FO would allow visualization of the lateral wall of the MC. Samii et al. (21) reported that the FS was found to be $15 \mathrm{~mm}$ anterolateral to the TG. However, we found that there 
Table I: Morphometric Measurements of Landmarks in the Middle Fossa and Anterior and Posterior Aspect of the Petrous Apex

\begin{tabular}{|c|c|c|c|c|c|c|}
\hline \multirow[t]{2}{*}{ Measured distance } & \multicolumn{2}{|c|}{ Right } & \multicolumn{2}{|l|}{ Left } & \multicolumn{2}{|c|}{ Mean } \\
\hline & Mean \pm SD & Range & Mean \pm SD & Range & Mean \pm SD & Range \\
\hline Length of TG $(A)$ & $16.0 \pm 1.01$ & $14.8-17.5$ & $16.1 \pm 1.05$ & $14.8-17.6$ & $16.1 \pm 1.01$ & $14.8-17.6$ \\
\hline Thickness of TG (B) & $2.44 \pm 0.17$ & $2.16-2.73$ & $2.60 \pm 0.17$ & $2.34-2.87$ & $2.52 \pm 0.19$ & $2.16-2.87^{*}$ \\
\hline Width of TG (C) & $3.74 \pm 0.17$ & $3.49-4.06$ & $3.81 \pm 0.18$ & $3.55-4.13$ & $3.78 \pm 0.18$ & $3.49-4.13^{*}$ \\
\hline Length of TI (D) & $10.3 \pm 1.42$ & $8.50-12.4$ & $10.6 \pm 1.33$ & $9.05-12.5$ & $10.5 \pm 1.36$ & $8.50-12.5^{*}$ \\
\hline Width of TI (E) & $7.66 \pm 1.24$ & $6.20-9.80$ & $7.62 \pm 1.21$ & $6.01-9.65$ & $7.64 \pm 1.20$ & $6.01-9.80$ \\
\hline Medial surface of posterior root of zygoma-MC (F) & $27.6 \pm 1.84$ & $25.1-30.8$ & $25.4 \pm 1.76$ & $22.9-28.3$ & $26.5 \pm 2.11$ & $22.9-30.8^{*}$ \\
\hline Lateral end of petrous ridge-MC(G) & $39.5 \pm 1.93$ & $37.1-43.1$ & $37.3 \pm 1.76$ & $34.8-40.3$ & $38.4 \pm 2.14$ & $34.8-43.1^{*}$ \\
\hline Arcuate eminence at petrous ridge- $\mathrm{MC}(\mathrm{H})$ & $16.1 \pm 1.30$ & 14.0-18.7 & $17.1 \pm 1.33$ & $15.2-19.3$ & $16.6 \pm 1.40$ & $14.0-19.3^{*}$ \\
\hline Facial nerve hiatus-MC (I) & $12.9 \pm 1.14$ & $11.5-14.9$ & $12.8 \pm 1.20$ & $11.2-14.9$ & $12.8 \pm 1.15$ & $11.2-14.9$ \\
\hline Foramen spinosum-MC(J) & $7.42 \pm 0.98$ & $6.01-8.97$ & $7.50 \pm 0.91$ & $6.02-8.73$ & $7.46 \pm 0.93$ & $6.01-8.97$ \\
\hline Foramen ovale-TG (K) & $5.55 \pm 0.36$ & $4.98-6.13$ & $6.05 \pm 0.35$ & $5.51-6.61$ & $5.81 \pm 0.43$ & $4.98-6.61^{*}$ \\
\hline Foramen ovale-TI(L) & $7.05 \pm 0.86$ & $5.75-8.35$ & $7.12 \pm 0.87$ & $5.88-8.65$ & $7.08 \pm 0.85$ & $5.75-8.65$ \\
\hline TG-CrVI (M) & $2.06 \pm 0.33$ & $1.55-2.62$ & $1.68 \pm 0.33$ & $1.21-2.35$ & $1.87 \pm 0.37$ & $1.21-2.62^{*}$ \\
\hline TG-CrIV (N) & $5.56 \pm 0.35$ & $4.98-6.12$ & $5.50 \pm 0.34$ & $4.95-6.13$ & $5.53 \pm 0.34$ & $4.95-6.13^{*}$ \\
\hline TG-Cr III (O) & $6.26 \pm 0.35$ & $5.75-6.85$ & $6.87 \pm 0.36$ & $6.25-7.45$ & $6.57 \pm 0.47$ & $5.75-7.45$ \\
\hline Posterior edge of SS-inferolateral edge of TP (P) & $42.7 \pm 1.88$ & $40.2-45.7$ & $44.5 \pm 1.90$ & $42.1-47.5$ & $43.6 \pm 2.07$ & $40.2-47.5^{*}$ \\
\hline Anterior edge of SS-inferolateral edge of TP (R) & $32.6 \pm 1.57$ & $30.2-35.4$ & $33.6 \pm 1.85$ & $30.8-36.5$ & $33.1 \pm 1.77$ & $30.2-36.5^{*}$ \\
\hline $\begin{array}{l}\text { Midpoint of anterior lip of IAM-inferolateral edge of } \\
\text { TP (S) }\end{array}$ & $7.11 \pm 0.85$ & $6.02-8.42$ & $7.28 \pm 0.80$ & $6.21-8.42$ & $7.19 \pm 0.81$ & $6.02-8.42^{*}$ \\
\hline Inferior petrosal sinus- lower edge of TP (T) & $11.9 \pm 0.92$ & $10.0-13.3$ & $12.9 \pm 0.78$ & $11.0-13.8$ & $12.4 \pm 0.97$ & $10.0-13.8^{*}$ \\
\hline
\end{tabular}

was a distance of at least $6.01 \mathrm{~mm}$ (mean, $7.46 \mathrm{~mm}$ ) from the FS to MC. Henderson et al. (11) noted that the distance between the TG and the FO ranged from 0 to $10 \mathrm{~mm}$. In the present study, we found that the distance varied from 4.98 to $6.01 \mathrm{~mm}$. The anterior edge of $\mathrm{MC}$, which approximately corresponds to the anterior limit of the TG, had a mean of $5.81 \mathrm{~mm}$ posterior to the edge of the FO. Henderson et al. (11) reported that the anterior edge of the TG was $3-4 \mathrm{~mm}$ anterior to the posterior lip of the FO in $8 \%$ and was $3-4 \mathrm{~mm}$ posterior to the foramen ovale in $7 \%$ of specimens. Chui et al. (3) reported that the anterior limit of the TG was seen 0-4.5 $\mathrm{mm}$ behind the $\mathrm{FO}$ on computer tomography scans of the heads. In our study, the TG was posterior to the posterior lip of the FO in all specimens. The relationship of the FO to the TG should be kept in mind during percutaneous fine needle aspiration biopsy or injection into the TG in view of these measurements. In the current study, the FO was $7.08 \mathrm{~mm}$ anterior to the $\mathrm{TI}$ which was occupied by the posterior root except for a small segment of the TG.

The anterior transpetrosal approach described by Kawase $(6,18,22)$ is used for mass lesions extending from MC to the posterior fossa. The GSPN is an important landmark during anterior petrosectomy (6). It is situated posterolateral to MC and courses medially from the facial nerve hiatus under the dura. By dissecting the GSPN lateral to the facial nerve hiatus, the geniculate ganglion was identified as a landmark defining the lateral extent of the internal acoustic canal (6). In our study, the facial nerve hiatus is found at to be $12.8 \mathrm{~mm}$ lateral to the MC. The relationship of the GSPN with the TG should be well understood. When dura from the anterior surface of the petrous bone is dissected, the GSPN and the geniculate ganglion are at risk for damage (21). Although the GSPN can be sectioned to avoid avulsion injury to the geniculate ganglion (6), preservation of the GSPN should be attempted in order to avoid postoperative "dry eye" from impaired lacrimation. By careful drilling anteriorly, the tip of the petrous apex can be removed and the undersurface of MC can be skeletonized. Attention is then directed to the horizontal segment of the petrous ICA. In previous studies (17) and in our study, MC was found to be just above the ICA and there was a periostal layer of MC or quite thin bony lamina between the TG and ICA. In our dissections, adult skull morphometry showed significant degrees of variability and there was a dehiscent ICA in approximately $30 \%$ of specimens. This variation should be kept in mind. The motor root of the trigeminal nerve should be identified early. According to our study, the GSPN along the lateral limit of the horizontal segment of the petrous ICA are important landmarks for identification of the vessel in this region. Tumors extending into the posterior and middle cranial fossae through the porus trigeminus can be removed 
via the cerebellopontine angle $(6,18,21,23,24)$. Anterior or posterior transpetrosal approaches are limited by the anterior wall of the IAM, the lower edge of the trigeminal nerve at the porus trigeminus, the inferior petrosal sinus, the petrous part of the ICA, the arcuate eminence and the basal turn of the cochlea $(6,18,20-21,23)$. Transpetrosal approaches provide a corridor between the ICA, the inferior petrosal sinus, and the trigeminal and facial nerves. When the posterolateral approach (retrosigmoid-suprameatal approach) is used to access MC (24), the first structure observed was the SS. The mean distance between the posterior wall of the SS and the TP was $43.6 \mathrm{~mm}$ and a mean of $33.1 \mathrm{~mm}$ from the anterior wall of the SS to the TP. Extreme care should be exercised when drilling the bone anterior to the IAM to avoid damaging the cochlea (1). It is not necessary to remove bone posterior to the IAM when performing posterior petrosectomy (20). Samii et al. (21) stated that, the mean distance between the IAM and MC was $6 \mathrm{~mm}$ from the posterior view thorough the cerebellopontine angle. Day et al. reported that IAM was 9.1 from the TP $(5,6)$. In our study, the TP was found to be $7.19 \mathrm{~mm}$ distant from the anterior wall of the IAM. The height of the inferior petrosal sinus, which is the inferior limit of exposure (the porus trigeminus distance) via a window created through posterior petrosectomy was $12.4 \mathrm{~mm}$. The superior petrosal vein should be preserved in order to prevent severe postoperative edema of the cerebellum and brain stem $(8,14-$ 15, 23).

Previous studies reported (11) that the length and thickness of the TG ranges from $15-25 \mathrm{~mm}$ and $4-5 \mathrm{~mm}$, respectively. Our findings differed from these; the measurements of TG varied from 14.8-17.6 $\mathrm{mm}$ and $2.16-2.87 \mathrm{~mm}$, respectively. This difference may be due to highly variable sizes of the TG as described by Chui et al. (3). Reliable anatomical landmarks are necessary for approaches to MC; however, there is variability in the morphometry of the skull base and surface morphometry of the petrous bone between right and left sides (Table 1). Such differences are accordance with the observations of Day et al. $(5,6)$.

Burr and Robinson (2) found that there was a well-defined subarachnoid space persisting with basal cisterns of the posterior fossa in the posterior aspect of the TG. Injection of any toxic substance into the TG may enter the subarachnoid space and result in neurological deficits (2). We identified cleavage planes between postganglionic trigeminal nerve rootlets. The fibers of the first division were dorsomedial, the second division fibers had an intermediate position and the third division fibers were ventrolateral. This relationship of rootlets should be kept in mind for selective rhizotomy of the trigeminal nerve.

\section{CONCLUSIONS}

Identification of surgical landmarks and awareness of their variations play an important role in approaching to MC. Measurements provided in the present study may serve in planning and choosing appropriate approaches to the MC.

\section{REFERENCES}

1. Ammirati M, Ma J, Cheatham ML, Maxwell D, Bloch J, Becker DP: Drilling the posterior wall of the petrous pyramid: Amicroneurosurgical anatomical study. J Neurosurg 78: 452-455, 1993

2. Burr HS, Robinson GB: An anatomical study of the gasserian ganglion with particular reference to the nature and extend of Meckel's Cave (M,C). Anatomical Record 29:269-282, 1925

3. Chui M, Tucker W, Hudson A, Bayer N: High resolution CT of Meckel's cave. Neuroradiology 27:403-409, 1985

4. Daniels DL, Pech P, Pojunas KW, Kilgore DP, Williams AL, Haughton VM: Trigeminal nerve: Anatomic correlation with MR imaging. Radiology 159:577-583, 1986

5. Day JD, Kellogg JX, Fukushima T, Giannotta SL: Microsurgical anatomy of the inner surface of the petrous bone: Neuroradiological and morphometric analysis as an adjunct to the retrosigmoid transmeatal approach. Neurosurgery 34:1003-1008, 1994

6. Day JD, Fukushima T, Giannotta SL: Microanatomical study of the extradural middle fossa approach to the petroclival and posterior cavernous sinus region: Description of the rhomboid construct. Neurosurgery 34:1009-1016, 1994

7. Giddings NA, Brackmann DE, Kwartler JA: Transcanal infracochlear approach to the petrous apex. Otolaryngol Head Neck Surg 104:29-36, 1991

8. Goel A, Nadkarni T: Basal lateral subtemporal approach for trigeminal neurinomas: Report of an experience with 18 cases. Acta Neurochir (Wien) 141:711-719, 1999

9. Gudmundsson K, Rhoton AL, Rushton JG: Detailed anatomy of the intracranial portion of the trigeminal nerve. J Neurosurg 35:592-600, 1971

10. Haberkamp TJ: Surgical anatomy of the transtemporal approaches to the petrous apex. Am J Otol 18:501-506, 1997

11. Henderson WR: The anatomy of the gasserian ganglion and the distribution of pain in relation to the injections and operations for trigeminal neuralgia. Ann R Coll Surg Engl 37:346-373, 1965

12. Janjua RM, Al-Mefty O, Densler DW, Shields CB: Dural relationships of Meckel cave and lateral wall of the cavernous sinus. Neurosurg Focus 25(6):E2, 2008

13. Kapila A, Chakeres DW, Blanco E: The Meckel cave: Computed tomographic study. Part I: Normal anatomy; Part II: Pathology. Radiology 152:425-433, 1984

14. Kassam $A B$, Prevedello $D M$, Carrau RL, Synderman $C H$, Gardner P, Osawa S, Seker A, Rhoton AL: The front door to meckel's cave: An anteromedial corridor via expanded endoscopic endonasal approach-technical considerations and clinical series. Neurosurgery 64(3 Suppl):71-82, 2009

15. Kinjo T, Mukawa J, Koga $H$, Shingaki T: An extensive cranial base meningioma extending bilaterally into Meckel's cave: Case report. Neurosurgery 40:615-617, 1997

16. Kobayashi M, Yoshida K, Kawase T: Inter-dural approach to parasellar tumors. Acta Neurochir (Wien) 152:279-284, 2010 
17. Leonetti JP, Smith PG, Linthicum FH: The petrous carotid artery: Anatomic relationships in skull base surgery. Otolaryngol Head Neck Surg 102:3-12, 1990

18. Miller CG, van Loveren HR, Keller JT, Pensak M, el-Kalliny M, Tew JM Jr: Transpetrosal approach: Surgical anatomy and technique. Neurosurgery 33:461-469, 1993

19. Rubinstein D, Stears RL, Stears JC: Trigeminal nerve and ganglion in the Meckel cave: Appearance at CT and MR imaging. Radiology 193:155-159, 1994

20. Slater PW, Welling DB, Goodman JH, Miner ME: Middle fossa transpetrosal approach for petroclival and brainstem tumors. Laryngoscope 108 (9):1408-1412, 1998

21. Samii M, Carvalho GA, Tatagiba M, Matthies C: Surgical management of meningiomas originating in Meckel's cave. Neurosurgery 41:767-775, 1997

22. Seo Y, Sasaki T, Nakamura H: Simple landmark for preservation of the cochlea during maximum drilling of the petrous apex through the anterior transpetrosal approach. Neurol Med Chir (Tokyo) 50:301-305, 2010
23. Taha JM, Tew JM Jr, van Loveren HR, Keller JT, el-Kalliny $M$ : Comparison of conventional and skull base surgical approaches for the excision of trigeminal neurinomas. J Neurosurg 82:719-725, 1995

24. Tanriover N, Abe H, Rhoton AL Jr, Kawashima M, Sanus GZ, Akar Z: Microsurgical anatomy of the superior petrosal venous complex: New classifications and implications for subtemporal transtentorial and retrosigmoid suprameatal approaches. J Neurosurg 106:1041-1050, 2007

25. Yousry I, Camelio S, Wiesmann M, Schmid UD, Moriggl B, Brückmann $H$, Yousry TA: Detailed magnetic resonance imaging anatomy of the cisternal segment of the abducent nerve: Dorello's canal and neurovascular relationships and landmarks. J Neurosurg 91:276-283, 1999

26. Ziyal IM, Salas E, Wright DC, Sekhar LN: The petrolingual ligament: The anatomy and surgical exposure of the posterolateral landmark of the cavernous sinus. Acta Neurochir (Wien) 140 (3):201-204, 1998 